\title{
The Mechanical Properties of a Novel STMR Damper Based on Magnetorheological Silly Putty
}

\author{
Xiao-Guo Lin, ${ }^{1,2}$ Fei Guo, ${ }^{3}$ Cheng-Bin Du $\mathbb{D}^{1},{ }^{1}$ and Guo-Jun Yu ${ }^{4}$ \\ ${ }^{1}$ Department of Engineering Mechanics, Hohai University, Nanjing 211100, China \\ ${ }^{2}$ School of Civil and Transportation Engineering, Ningbo University of Technology, Ningbo 315211, China \\ ${ }^{3}$ MCC Huatian Engineering \& Technology Corporation, Nanjing 210019, China \\ ${ }^{4}$ Faculty of Civil Engineering and Mechanics, Jiangsu University, Zhenjiang 212013, China \\ Correspondence should be addressed to Cheng-Bin Du; cbdu@hhu.edu.cn
}

Received 6 February 2018; Accepted 10 April 2018; Published 25 June 2018

Academic Editor: Kestutys Baltakys

Copyright $\odot 2018$ Xiao-Guo Lin et al. This is an open access article distributed under the Creative Commons Attribution License, which permits unrestricted use, distribution, and reproduction in any medium, provided the original work is properly cited.

\begin{abstract}
A novel shear thickening magnetorheological (STMR) damper with both speed locking and semiactive controlling properties was designed and fabricated based on multifunctional smart composite materials which was defined as magnetorheological Silly Putty (MRSP). The rate sensitive property and magnetorheological effect of MRSP samples were analyzed by using a rheometer to select the best filler for the STMR damper. The mechanical properties of the STMR damper were investigated through slow, fast, and dynamic experiments. The experimental results indicate that the STMR damper exhibits an obvious rate sensitive characteristic and semiactive control property. On one hand, when the STMR damper is simulated fast enough, it can realize the "speed switch" function, which enables it to instantly lock up and act as a shock transmission unit (STU). On the other hand, when the STMR damper is applied with current, the damping force can be adjusted by magnetic field strength to realize its semiactive controlling property. In addition, a multiparameter and symmetry model was established to describe the dynamic hysteretic behavior of the STMR damper, which is consistent with the experimental data.
\end{abstract}

\section{Introduction}

Magnetorheological Silly Putty (MRSP) is a smart multifunctional composite prepared by dispersing soft magnetic particles into a Silly Putty matrix with shear stiffening property [1]. This new kind of smart material is the solid state of the magnetorheological shear thickening fluid (MRSTF) proposed by Zhang et al. and Peng et al. [2, 3]. Subsequently, Wang et al. $[4,5]$ first developed a magnetically responsive shear-stiffening gel with excellent shear stiffening performance and magnetorheological effect. This novel magnetically responsive shear-stiffening gel can provide credible tunability with external stimuli.

At this stage, the vibration damper based on a single magnetorheological material requires an external magnetic field, which belongs to the active device. Magnetorheological materials are widely used in all kinds of MR dampers, and the technology is relatively mature. Lord Company of USA and
BASF Company of Germany have developed many commercialized MR dampers. For example, the RD-1005-type MR damper produced by Lord Company is the earliest application of the international commercialized MR damper with damping force over $2200 \mathrm{~N}$ [6]. MR dampers designed for large civil engineering structures show greater structure size and damping force output. Qu et al. developed a full-scale MR damper output of up to $500 \mathrm{kN}$, carried out a study on the key technologies of the leakproof design of the magnetic field and builtin butterfly spring, and finally applied the full size MR damper to a highway railway cable-stayed bridge with semiactive vibration control [7-10]. Yu et al. developed the self-decoupled magnetorheological (SDMR) damper, which produced the largest output of $360 \mathrm{kN}$. The displacement decoupling mechanism was set up in the damper, and permanent magnets were arranged to provide the function of self-protection. The SDMR damper was mainly applied to the semiactive vibration control of frame and grid structures [11-14]. 
The single shear thickening material is used as energy dissipation fillers for small passive ST dampers. Zhang et al. developed a speed-driven damper based on the shear thickening fluid and studied the dynamic performance of the ST damper through both experiment and theory methods [15]. These results confirm that the ST damper presents higher stiffness and damping at high-speed dynamic loading than those at low-speed loading and absorbs more energy. Zhou et al. developed a double-out rod-type ST damper filled by shear thickening fluid of a high-concentration polystyreneethyl acrylate nanometer particle suspension. The dynamical experiment results reveal that with the increase in excitation frequency, the storage modulus and energy dissipation modulus rapidly increase, and the output of the ST damper dramatically boosts, exhibiting great absorption and energy dissipation capacity; the maximum energy dissipation modulus reached up to $21 \mathrm{kPa}$ [16]. The most common application of shear thickening materials in civil engineering structures is the shock transmission unit (STU), which is a device resembling a speed switch. It is basically approximating to a general damper in appearance and internal structure, which is composed of a piston and cylinder and regarded as a special damper. Silly Putty has become a promising material for the special damper of STU, which is widely used in the multispan bridge [17].

The MR damper is the most mature energy dissipation device in the field of magnetorheological vibration damping. From the point of energy, the principle of the work is to change the energy spectrum of the vibration source's excitation to the system and reduce the passed energy to suppress the vibration. However, in the face of huge incentive loads, the vibration damping, which the MR damper depends on, does not slow down the deformation or even destruction of civil engineering structures due to insufficient stiffness; besides, the mechanism of damping is relatively simple. In addition, these MR dampers all belong to active devices, which means that in the event of a circuit failure that cannot be controlled by a magnetic field, the damper loses the significance of the semiactive vibration control. The current solutions include setting a permanent magnet to make the magnetorheological fluid in the MR damper produce certain yield strength, but the scheme makes the design of the damper more complex. Furthermore, commonly used permanent magnets are made of $\mathrm{NdFeB}$ material with strong temperature instability, meaning that the higher the temperature, the faster the demagnetization. The shear thickening material is mainly used in caging devices, including all kinds of speed locking devices, in order to improve the overall stiffness of the structure and achieve the purpose of seismic resistance and vibration reduction. At the moment, researchers of the world only focus on the study of the mechanisms of magnetorheological damping and shear thickening damping respectively, and there is no intersection between each other. However, there are no relevant studies that combine the characteristics of two kinds of intelligent materials as a whole to explore new intelligent dampers with double vibration damping mechanisms.

In this work, a novel shear thickening magnetorheological (STMR) damper was designed and fabricated
Table 1: Composition of the Silly Putty matrix.

\begin{tabular}{lc}
\hline Composition & Weight percentage \\
\hline Polydimethylsiloxane (PDMS) & 65 \\
Silica & 17 \\
Thixotrol & 9 \\
Boric acid & 4 \\
Glycerine & 1 \\
Titanium dioxide & 1 \\
Dimethyl cyclosiloxane & 1 \\
\hline
\end{tabular}

based on MRSPs. Compared with traditional MR dampers, the STMR damper not only exhibited controllable characteristics of damping force under the adjustment of the magnetic field but also provided a "locking" function under an unexpected sudden rare load, which was more suitable for the vibration control of large civil engineering structures. In order to verify the dual vibration damping characteristics of the STMR damper, slow, fast, and dynamic mechanical property experiments were carried out. Finally, a multiparameter and symmetry model was established and deduced to describe the dynamic hysteretic behavior of the STMR damper.

\section{Experimental Section of MRSPs}

2.1. Materials. The Dow Corning 3179 dilatant compound, which was purchased from Dow Corning Co., Ltd., was used as the Silly Putty matrix. The composition of the Silly Putty matrix is outlined in Table 1. Polydimethylsiloxane (PDMS) as a commonly used organic silicon material is the major constituent of the composition. The soft magnetic particles of the carbonyl iron (CI) with an average size of $3.5 \mu \mathrm{m}$ were purchased from Jiangsu Tianyi Ultra-fine metal powder Co. Ltd. (Xuyi, China).

2.2. Preparation and Testing of MRSPs. The dilatant compound as matrix and the different volume fractions of $\mathrm{CI}$ as fillers were homogeneously mixed using a two-roll mill (Nantong Hailite Rubber Machinery Inc., China, XK-160 model) at room temperature. For the mechanical mixing method, up to six different volume fractions were considered for the present study: $0,6.98,10.11,15.84,20.80$, and $27.29 \%$. The prepared samples were marked as MRSP 0, MRSP 1, MRSP 2, MRSP 3, MRSP 4, and MRSP 5, in sequence. In this work, the dynamic rheological properties of the MRSP samples were carried out using a commercial rheometer (Physica MCR 302, Anton Paar Co., Austria). During the testing procedure, a parallel plate PP20 with a diameter of approximately $20 \mathrm{~mm}$ was used, and a gap of $1 \mathrm{~mm}$ was maintained at all times. At the same time, a controllable magnetic field was generated by an external coil. Besides, all the samples for the experiment were maintained at an approximately same volume value. The MRSP sample and MCR 302 rheometer are displayed in Figure 1.

\section{Experimental Section of the STMR Damper}

3.1. Designing of STMR Damper. The structure of the STMR damper is shown in Figure 2, with its appearance 


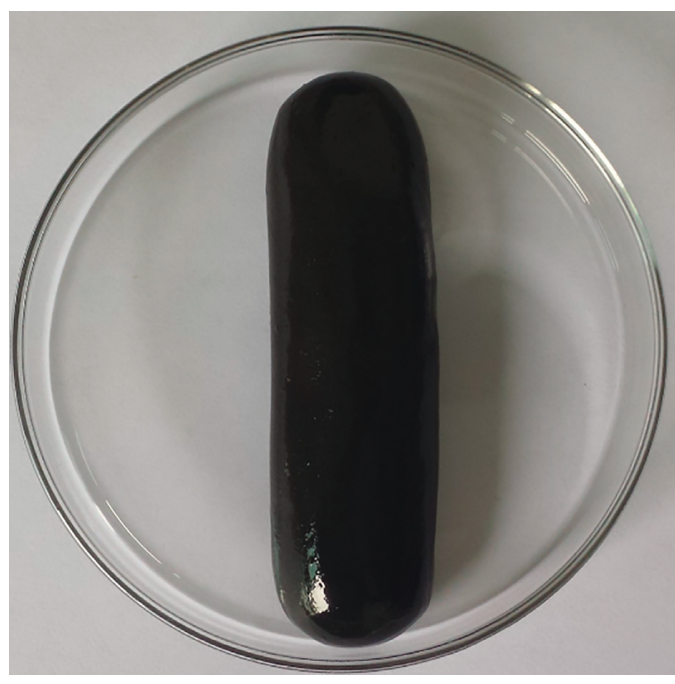

(a)

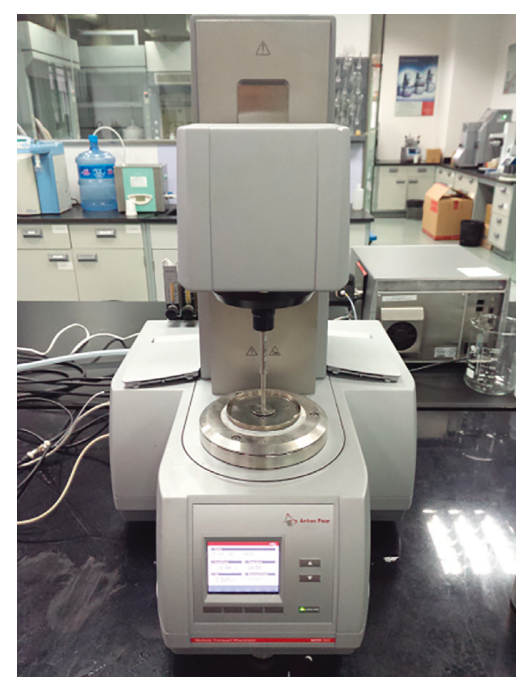

(b)

FIgure 1: Preparation of (a) the MRSP sample and (b) the MCR 302 rheometer.

approximating to a traditional MR damper, mainly consisting of the main cylinder tube, accessory cylinder tube, auxiliary cylinder, main piston, accessory piston, and piston rod. The filling material in the main cylinder exhibits highMR effect, while the inner filling material of the auxiliary cylinder presents a higher shear stiffening effect to improve the overall safety reserve. So, both the main cylinder and auxiliary cylinder are combined together into a cooperative cylinder. The main piston and auxiliary piston are arranged on the piston rod, the main piston and piston rod are connected with the method of a rigid threaded connection, and two circular excitation coils are detoured in two opposite directions on the main piston. Each of the two excitation coils connects one wire to the external power supply through the traverse channel, and the power mode is in the paralleling way. The accessory piston is connected with the piston rod through the butterfly spring and allows it to move along the piston rod within the maximum compression amount of the spring, in order to realize the decoupling function. The filling materials in the main and auxiliary cylinders generate flow and deformation in their own working gaps.

The STMR damper mainly consists of the main cylinder controlled by magnetorheology and the accessory cylinder with displacement decoupling characteristic. This novel damper not only maintains the performance of an adjustable damping force by magnetic field, but also possesses obvious rate sensitive characteristic which provides the function of locking structure to disperse loading under high frequency or impaction. The basic structural parameters of the STMR damper are listed in Table 2.

3.2. Testing of the STMR Damper. The physical object of the STMR damper is displayed in Figure 3. The energy dissipation of the STMR damper is mainly triggered by the flow and deformation of the filling materials. The rate sensitive characteristic and magnetorheological effect of MRSPs are the internal reasons for the damper to adapt to environmental incentives and directional intelligent controllability. In order to verify the rate sensitivity and magnetic control characteristics of the STMR damper, the mechanical properties were investigated by the SDS-300 electrohydraulic servostatic and dynamic testing machine. The main contents of the testing included the following: (1) the influence of different rates on the mechanical properties of the damper under slow and fast axial tension conditions; (2) the influence of different frequencies and different current excitations on the dynamic hysteretic properties of the damper under large and small displacements. The installation of the testing machine for the STMR damper is displayed in Figure 4. In the testing procedure, a current excitation with an adjustable DCregulated power supply was adopted, and the maximum input current was $3 \mathrm{~A}$. In each experiment, the piston carried on the reciprocating movement from the balance position, which was mainly located in the middle position between the main and accessory cylinder tubes. In the damper structure diagram, the limit stroke of the piston was $65 \mathrm{~mm}$, and in the present experiment of dynamic mechanical properties, the amplitude of the large displacement was $55 \mathrm{~mm}$.

\section{Results and Discussion}

4.1. Rate Sensitive Characteristic of MRSPs. In the earlier research, when there was no external magnetic field applied, the soft magnetic particles of CI were evenly dispersed in the Silly Putty matrix to form isotropic viscoelastic materials [1]. From this point, the CI powder was considered as a general particle filling, which played a role in strengthening the matrix material. The larger the volume fraction of the CI particle is, the greater the shear storage modulus of the sample becomes, which is in consistent with the 


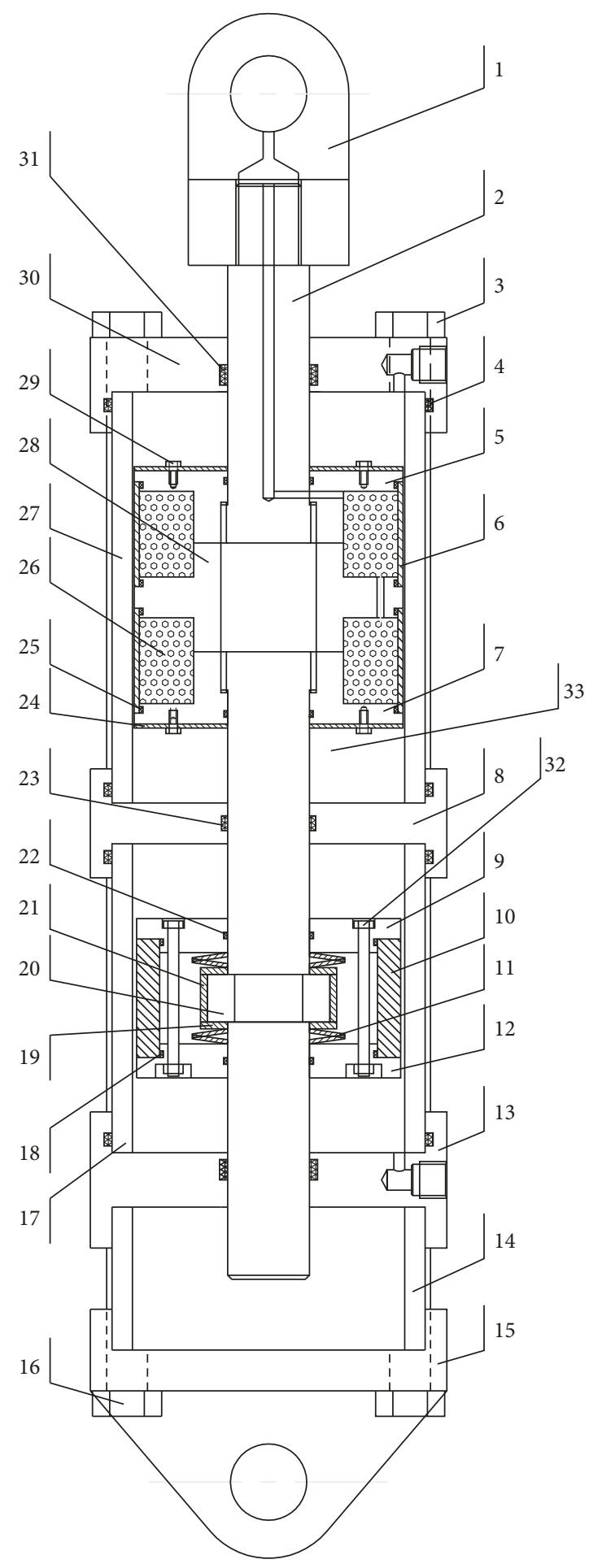

\begin{tabular}{|c|c|c|}
\hline \multicolumn{3}{|c|}{ Assembly drawing of STMR damper } \\
\hline $\begin{array}{l}\text { Serial } \\
\text { Number }\end{array}$ & Name & Quantity \\
\hline 1 & Single earring for axial use & 1 \\
\hline 2 & Piston rod & 1 \\
\hline 3 & Pull rod bolt 1 & 4 \\
\hline 4 & Seal ring of type $\mathrm{O}$ & 4 \\
\hline 5 & Main piston 1 & 1 \\
\hline 6 & Coil sleeve & 1 \\
\hline 7 & Main piston 2 & 1 \\
\hline 8 & Connecting cylinder cover 1 & 1 \\
\hline 9 & Accessory piston 1 & 1 \\
\hline 10 & Accessory piston sleeve & 1 \\
\hline 11 & Butterfly spring & 4 \\
\hline 12 & Accessory piston 2 & 1 \\
\hline 13 & Connecting cylinder cover 2 & 1 \\
\hline 14 & Auxiliary cylinder tube & 1 \\
\hline 15 & Back end cover & 1 \\
\hline 16 & Pull rod bolt 2 & 4 \\
\hline 17 & Accessory cylinder tube & 1 \\
\hline 18 & Seal ring of type O & 2 \\
\hline 19 & Sleeve baffle & 2 \\
\hline 20 & Semiring & 2 \\
\hline 21 & Semiring sleeve & 1 \\
\hline 22 & Seal ring of type O & 2 \\
\hline 23 & Seal ring of type $\mathrm{O}$ & 1 \\
\hline 24 & $\begin{array}{l}\text { Magnetically isolated } \\
\text { copper piece }\end{array}$ & 2 \\
\hline 25 & Seal ring of type $\mathrm{O}$ & 4 \\
\hline 26 & Coil & 1 \\
\hline 27 & Main cylinder tube & 1 \\
\hline 28 & Main piston 3 & 1 \\
\hline 29 & Screw & 8 \\
\hline 30 & Front end cover & 1 \\
\hline 31 & Seal ring of type $Y x$ & 2 \\
\hline 32 & Hexagon head bolt & 4 \\
\hline 33 & Filling materials & 2 \\
\hline
\end{tabular}

FIgURE 2: Basic structure of the STMR damper.

empirical formula (1). This formula explains the rule of shear modulus varying with the volume fraction of rigid particles randomly filled in the rubber matrix [18]. The addition of rigid particles leads to the decrease in internal motion space within the matrix, which further promotes the interaction between the molecular chains. Simultaneously, more obvious obstacles are encountered in solving the entanglement of the molecular chains, which shows the escalation in shear storage modulus on a macroscopic point of view [5]:

$$
G_{\text {ran }}=G_{0}\left(1+2.5 \phi+14.1 \phi^{2}\right),
$$

where $G_{\text {ran }}$ refers to the shear modulus of composites filled with rigid particle composites, $G_{0}$ is the shear modulus of the 
TABLE 2: Main structure parameter of the STMR damper.

\begin{tabular}{|c|c|c|c|}
\hline Working gap of the main cylinder tube & $2 \mathrm{~mm}$ & Working gap of the accessory cylinder & $2 \mathrm{~mm}$ \\
\hline External diameter of the main piston & $156 \mathrm{~mm}$ & External diameter of the accessory piston & $156 \mathrm{~mm}$ \\
\hline Wall thickness of steel tube of the main & $15 \mathrm{~m}$ & $\begin{array}{l}\text { Wall thickness of steel tube of the accessory cylinder } \\
\text { tube }\end{array}$ & $15 \mathrm{~mm}$ \\
\hline Piston's s & $65 \mathrm{mn}$ & Piston's stroke limit of the accessory cylinder tube & $65 \mathrm{~mm}$ \\
\hline Length of working gap of the main cylinder tube & $206 \mathrm{~mm}$ & Length of working gap of the accessory cylinder tube & $117 \mathrm{~mm}$ \\
\hline $\begin{array}{l}\text { Piston's number of windings of the main cylinder } \\
\text { tube }\end{array}$ & 980 & Effective stroke of decoupling spring & $7 \mathrm{~mm}$ \\
\hline Diameter of piston rod & $50 \mathrm{~mm}$ & Maximu & $<120 \mathrm{~W}$ \\
\hline Piston's current range of the main cylinder tube & $0 \sim 3 \mathrm{~A}$ & Designed damping force & $300 \mathrm{kN}$ \\
\hline
\end{tabular}

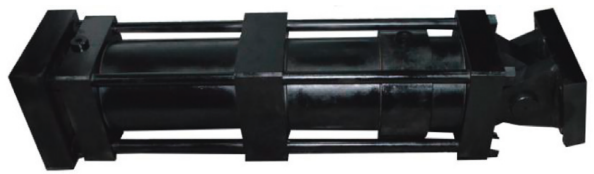

FIGURE 3: Entity of the STMR damper.

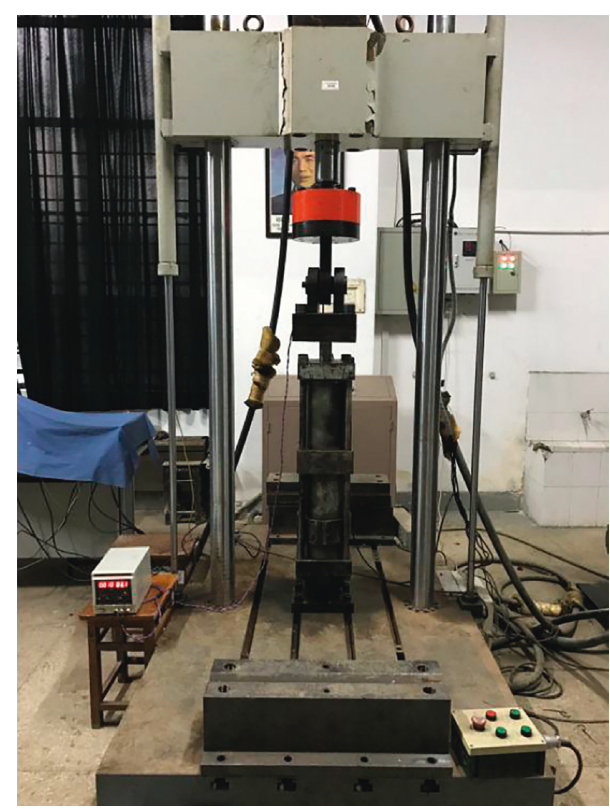

FIgURE 4: The experimental setup of the STMR damper.

matrix material without the filling of rigid particles, and $\phi$ means the volume fraction of rigid particles.

Besides, from the earlier research, in order to compare the shear stiffening degree of the MRSP samples, the absolute shear stiffening effect (ASTe) and relative shear stiffening effect (RSTe) are defined as the index of measurement [1], as shown specifically in the following formula:

$$
\begin{aligned}
\mathrm{ASTe} & =G_{\text {max }}^{\prime}-G_{\text {min }}^{\prime}, \\
\mathrm{RSTe} \% & =\frac{G_{\text {max }}^{\prime}-G_{\text {min }}^{\prime}}{G_{\text {min }}^{\prime}} \times 100 \%,
\end{aligned}
$$

where $G_{\max }^{\prime}$ stands for the maximum shear storage modulus excited by the loading frequency and $G_{\min }^{\prime}$ refers to the initial shear storage modulus. When the angular frequency increases, the MRSP samples exhibit an obvious rate sensitive characteristic and a sharply increased storage modulus, together with the demonstration that the sample "hardens." Furthermore, the higher the content of the CI powder is, the more beneficial it is to the absolute shear stiffening effect of the material. In earlier research [1], for the MRSP 5 sample, under normal temperatures, the absolute modulus change is $0.6145 \mathrm{MPa}$, which equals to approximately twice the pure shear stiffening matrix MRSP 0, while the relative shear stiffening effect is $1412.64 \%$, which is far less than $77584.21 \%$ of the pure shear stiffening matrix MRSP 0 .

However, under the condition of an external magnetic field, the soft magnetic particles of the CI powder were arranged into chain-like ordered structures along the direction of the magnetic flux line in the interior of the shear stiffening matrix, forming the anisotropic structure. The pure shear stiffening matrix MRSP 0 sample was not influenced by the magnetic field due to the absence of soft magnetic particle fillings. Figure 5 illustrates the relationship between shear storage modulus of the MRSP samples with different contents of soft magnetic particles and the angular frequencies separately under different external magnetic fields, in which the angular frequency is $1-100 \mathrm{rad} / \mathrm{s}$ with continuous change. It is observed from the diagram that with the strength of the exerted magnetic field enhancing, the shear storage modulus of the sample increases as well. For the MRSP 5 sample, the maximum storage modulus after shear stiffening is approximately $0.5 \mathrm{MPa}$ under the condition of zero magnetic field. Nonetheless, under the constant magnetic flux density of $0.627 \mathrm{~T}$, the maximum storage modulus after shear stiffening is up to $2.3 \mathrm{MPa}$, and the magneto-induced modulus caused by the magnetic field equals to approximately $1.8 \mathrm{MPa}$. For the transverse comparison between different samples, when the content of the CI powder rises up, the storage modulus at the same magnetic flux density keeps an upward tendency. The maximum storage modulus of the MRSP 1 sample under a magnetic flux density of $0.627 \mathrm{~T}$ is $0.6 \mathrm{MPa}$, while the particle mass fraction of MRSP 5 reaches twice as much as that of MRSP 1, but the maximum modulus equals to approximately four times as that of MRSP 1. On one hand, no matter how the soft magnetic particles are randomly filled or arranged in the matrix with a certain ordered structure, under the situation that the content of soft magnetic particles grows up, the reinforcement effect of the material increases. On the other hand, previous studies expose that the higher the 

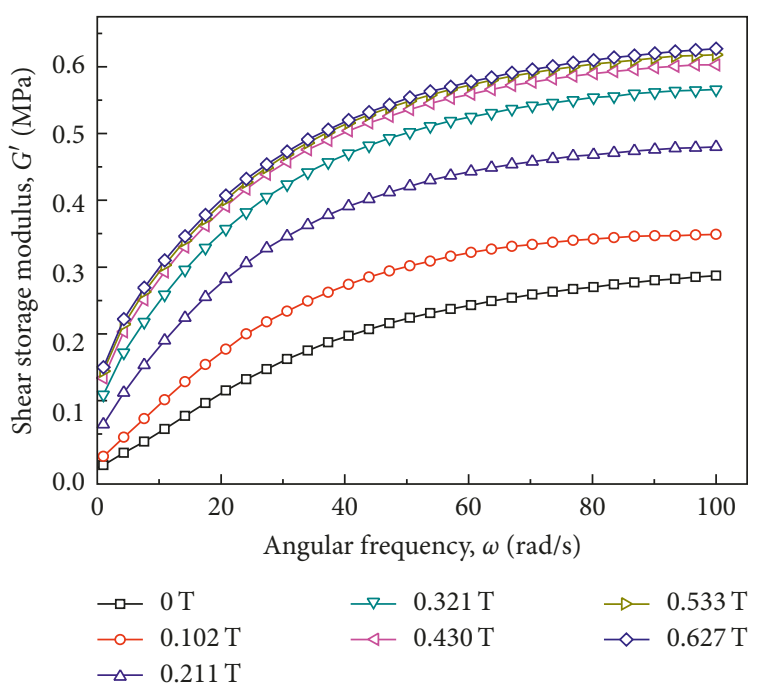

(a)

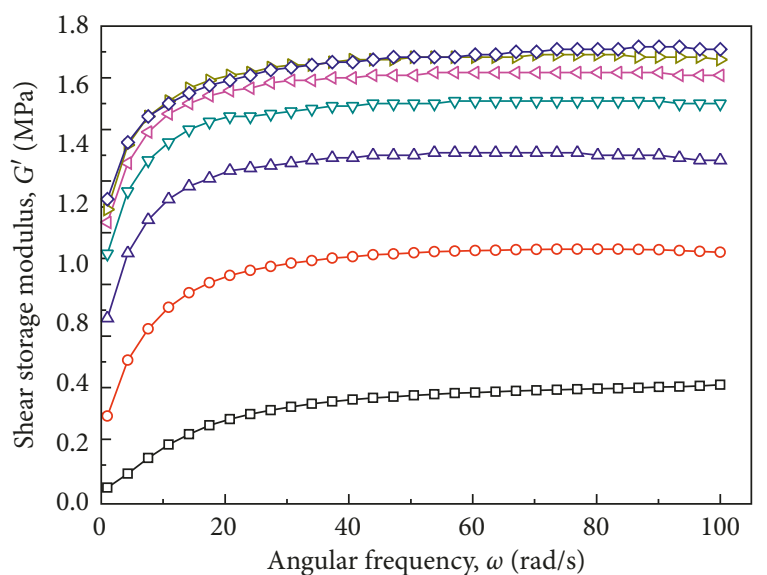

$$
\begin{array}{lll}
\rightarrow-0 \mathrm{~T} & \rightarrow 0.321 \mathrm{~T} & \rightarrow 0.533 \mathrm{~T} \\
\multimap 0.102 \mathrm{~T} & \smile 0.430 \mathrm{~T} & \neg 0.627 \mathrm{~T} \\
\square-0.211 \mathrm{~T} & &
\end{array}
$$

(c)

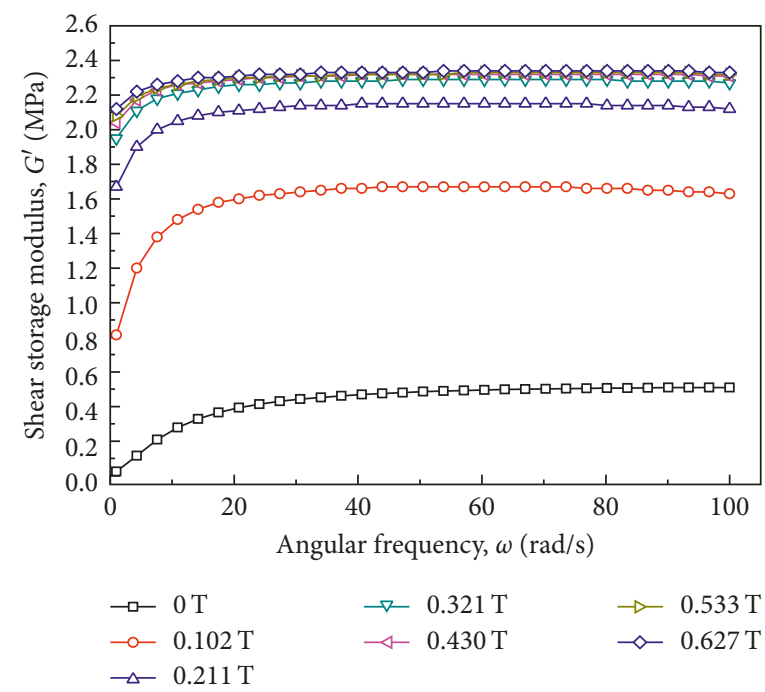

(e)

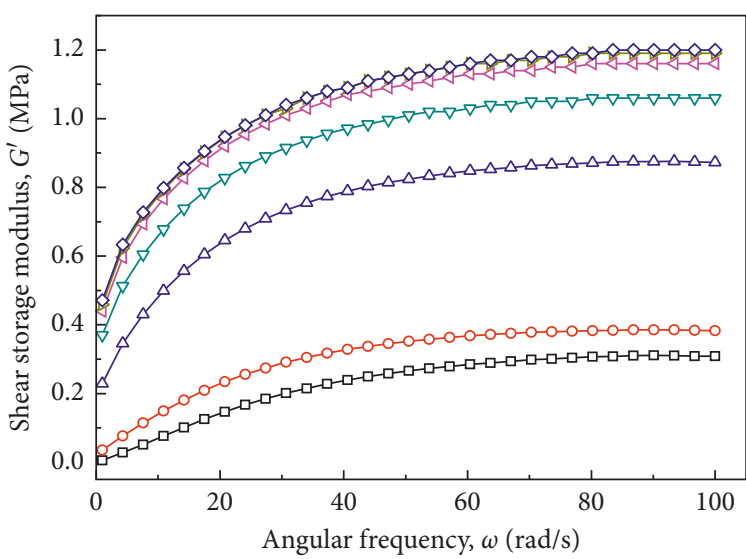

$$
\begin{array}{lll}
\rightarrow 0 \mathrm{~T} & \rightarrow 0.321 \mathrm{~T} & \rightarrow 0.533 \mathrm{~T} \\
\neg-0.102 \mathrm{~T} & \smile-0.430 \mathrm{~T} & \neg 0.627 \mathrm{~T} \\
\triangle 0.211 \mathrm{~T} & &
\end{array}
$$

(b)

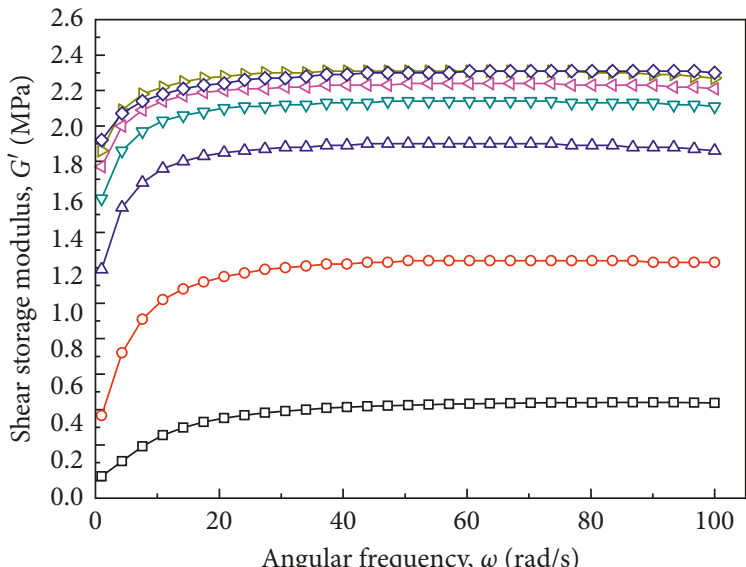

$$
\begin{array}{lll}
\rightarrow 0 \mathrm{~T} & \rightarrow 0.321 \mathrm{~T} & \rightarrow 0.533 \mathrm{~T} \\
\multimap-0.102 \mathrm{~T} & \smile 0.430 \mathrm{~T} & \neg 0.627 \mathrm{~T}
\end{array}
$$$$
\triangle 0.211 \mathrm{~T}
$$

(d) 
TABle 3: $G_{\max }^{\prime}, G_{\min }^{\prime}$, ASTe, and RSTe of the MRSP samples.

\begin{tabular}{|c|c|c|c|c|c|}
\hline Samples & Magnetic flux density, $B(\mathrm{~T})$ & $G_{\max }^{\prime}(\mathrm{MPa})$ & $G_{\min }^{\prime}(\mathrm{MPa})$ & $\mathrm{ASTe}(\mathrm{MPa})$ & RSTe (\%) \\
\hline \multirow{7}{*}{ MRSP 1} & 0 & 0.287 & 0.00346 & 0.28354 & 8194.80 \\
\hline & 0.102 & 0.349 & 0.01620 & 0.33280 & 2054.32 \\
\hline & 0.211 & 0.480 & 0.06410 & 0.41590 & 648.83 \\
\hline & 0.321 & 0.566 & 0.10900 & 0.45700 & 419.27 \\
\hline & 0.430 & 0.603 & 0.13400 & 0.46900 & 350 \\
\hline & 0.533 & 0.618 & 0.14400 & 0.47400 & 329.17 \\
\hline & 0.627 & 0.627 & 0.15000 & 0.47700 & 318 \\
\hline \multirow{7}{*}{ MRSP 2} & 0 & 0.309 & 0.00531 & 0.30369 & 5719.21 \\
\hline & 0.102 & 0.383 & 0.03550 & 0.34750 & 978.87 \\
\hline & 0.211 & 0.873 & 0.22900 & 0.64400 & 281.22 \\
\hline & 0.321 & 1.060 & 0.37000 & 0.69000 & 186.49 \\
\hline & 0.430 & 1.160 & 0.44000 & 0.72000 & 163.64 \\
\hline & 0.533 & 1.190 & 0.45900 & 0.73100 & 159.26 \\
\hline & 0.627 & 1.200 & 0.47100 & 0.72900 & 154.78 \\
\hline \multirow{7}{*}{ MRSP 3} & 0 & 0.411 & 0.0131 & 0.39790 & 3037.40 \\
\hline & 0.102 & 0.924 & 0.2900 & 0.63400 & 218.62 \\
\hline & 0.211 & 1.280 & 0.6690 & 0.61100 & 91.33 \\
\hline & 0.321 & 1.500 & 0.9190 & 0.58100 & 63.22 \\
\hline & 0.430 & 1.610 & 1.0400 & 0.57000 & 54.81 \\
\hline & 0.533 & 1.670 & 1.0900 & 0.58000 & 53.21 \\
\hline & 0.627 & 1.710 & 1.1300 & 0.58000 & 51.33 \\
\hline \multirow{7}{*}{ MRSP 4} & 0 & 0.44 & 0.0228 & 0.41720 & 1829.82 \\
\hline & 0.102 & 1.24 & 0.366 & 0.87400 & 238.80 \\
\hline & 0.211 & 1.90 & 1.19 & 0.71 & 59.66 \\
\hline & 0.321 & 2.14 & 1.59 & 0.55 & 34.59 \\
\hline & 0.430 & 2.24 & 1.77 & 0.47 & 26.55 \\
\hline & 0.533 & 2.31 & 1.86 & 0.45 & 24.19 \\
\hline & 0.627 & 2.31 & 1.92 & 0.39 & 20.31 \\
\hline \multirow{7}{*}{ MRSP 5} & 0 & 0.51 & 0.0239 & 0.4861 & 2033.89 \\
\hline & 0.102 & 1.67 & 0.814 & 0.8560 & 105.16 \\
\hline & 0.211 & 2.15 & 1.67 & 0.48 & 28.74 \\
\hline & 0.321 & 2.29 & 1.95 & 0.34 & 17.44 \\
\hline & 0.430 & 2.32 & 2.04 & 0.28 & 13.73 \\
\hline & 0.533 & 2.33 & 2.08 & 0.25 & 12.02 \\
\hline & 0.627 & 2.34 & 2.12 & 0.22 & 10.38 \\
\hline
\end{tabular}

volume fraction of particles, the denser the chain-like ordered structures form under the same magnetic field condition, which leads to the increasing of the magneto-induced modulus.

Similarly, the ASTe and RSTe indexes are implemented to illustrate the influence of magnetic flux density on the shear stiffening effect of the MRSP samples, and the relevant parameters are listed in Table 3. It is perceived that for samples with low content of soft magnetic particles, such as MRSP 1 and MRSP 2, the magnetic flux density is conducive to the promotion of the shear stiffening effect of the MRSP samples. The greater the magnetic flux density is, the more superior the value of the ASTe becomes. For samples with volume fraction of soft magnetic particle up to $15 \%$, such as MRSP 3, MRSP 4, and MRSP 5, the influence of magnetic flux density on absolute shear stiffening effect is relatively complex. With the increase of magnetic flux density, ASTe presents a tendency of falling down after ascending first, which demonstrates that only under weak magnetic field conditions (no more than $0.1 \mathrm{~T}$ ), it becomes conducive to the absolute shear stiffening effect of high particle content samples. Besides, with the increase of magnetic flux density, the initial shear storage modulus of the samples significantly intensifies, while the relative shear stiffening effect of samples declines, and the RSTe value decreases. However, for the transverse comparison between different samples, under the zero magnetic field conditions, the higher the particle content of the sample becomes, the greater the absolute shear stiffening effect it achieves, which is in line with the previous description. As the intensity of the magnetic field increases for the samples with the higher particle content, the ASTe value becomes smaller. When the magnetic flux density is $0.627 \mathrm{~T}$, the change in the absolute modulus of MRSP 2 is $0.729 \mathrm{MPa}$. Nevertheless, with the increase of particle content, the ASTe value of the sample subsequently declines, and in addition, the absolute modulus of MRSP 5 drops to only $0.22 \mathrm{MPa}$. Under zero magnetic field condition, the filling of soft magnetic particles plays a certain positive role in the absolute modulus change in the MRSP samples. As the magnetic flux density increases, the ordered structure of the soft magnetic particles in the interior of the matrix becomes more complex. The larger the volume fraction is, the closer the connections 
become between particles and particles and between chain and chain, thereby providing partial support for the macroscopic shear modulus. However, the movement of the matrix molecular chains is greatly hindered due to the decrease of internal motion space within the matrix. From the viscoelastic aspect, it is not beneficial to the relaxation and rebalance process of the high molecular polymer, which leads to the reduction of the absolute shear stiffening effect of the samples. Therefore, for the MRSP samples with a high content of soft magnetic particles, in order to give full play to the characteristic of shear stiffening, the external magnetic field in its working environment should not be too large.

4.2. Magnetorheological Effect of MRSPs. Under a continuously changing magnetic field, the soft magnetic particles are rapidly magnetized into dipoles and are arranged into chainlike ordered structures within the interior of the matrix until the magnetic saturation is achieved. Macroscopically, the continuous variation of the shear modulus of the MRSPs eventually reaches a steady state of saturation. The magnetorheological effect determines the directional controllable performance of the MRSPs, which is usually measured by the change of modulus. Currently, the research results indicated that the lower the loading frequency was, the higher the magnetorheological effect became, and the more the conducive it was to the adjustment of the magnetic field. However, the loading frequency was higher, the matrix modulus of MRSP became larger, the chain-like resistance of soft magnetic particles in the interior of the matrix became greater, and the magnetorheological effect tended to be lower [1]. Figure 6 reveals the varied relationship between the shear storage modulus and magnetic flux density of different samples under the conditions of different shear strain, low load frequency ( $\omega=1 \mathrm{rad} / \mathrm{s})$, and magnetic flux density continuous changing from 0 to $0.894 \mathrm{~T}$. Correspondingly, the larger the shear strain is, the smaller the storage modulus of the sample becomes. As the magnetic flux density enhances, the shear storage modulus rapidly increases before $0.4 \mathrm{~T}$ and gradually tends to magnetic saturation after $0.4 \mathrm{~T}$. Likewise, the absolute magnetorheological effect (AMRe) and relative magnetorheological effect (RMRe) are adopted as the indexes for the performance of magnetic field adjustment, as shown in the following equation:

$$
\begin{aligned}
\operatorname{AMRe} & =G_{\text {max }}^{\prime}-G_{\text {min }}^{\prime}, \\
\operatorname{RMRe} \% & =\frac{G_{\text {max }}^{\prime}-G_{\text {min }}^{\prime}}{G_{\text {min }}^{\prime}} \times 100 \%,
\end{aligned}
$$

where $G_{\max }^{\prime}$ means the maximum shear storage modulus when reaching magnetic saturation, while $G_{\min }^{\prime}$ is the initial shear storage modulus under zero magnetic field. The correlated results of all the curves in Figure 6, which are calculated according to (3), are listed in Table 4.

For the transverse comparison of the samples with different contents of soft magnetic particles, the larger the volume fraction of soft magnetic particles is, the greater the magneto-induced modulus becomes, and the more obvious the absolute magnetorheological effect tends to be. For MRSP 5 with the highest particle content, the magnetoinduced modulus is up to $1.5 \mathrm{MPa}$ at the strain of $0.5 \%$. The relative magnetorheological effect is mainly determined by the initial shear storage modulus, from which it can be observed that, for loading conditions at small strains of $0.5 \%$ and $1 \%$, the relative magnetorheological effect produced by the same sample varies with no obvious difference from each other. This is for the reason that within the strain of $1 \%$, each group of MRSP sample is in the linear viscoelastic region, which displays no obvious difference of initial modulus. However, when the strain continues to climb up to $5 \%$ and $10 \%$, respectively, the initial modulus sharply decreases outside the linear viscoelastic region, and in turn, the magnetorheological effect becomes quite different. Besides, the relative magnetorheological effect with strain of $10 \%$ is higher than that with the strain of $5 \%$. With the increase in the content of $\mathrm{CI}$ powder, the relative magnetorheological effect tends to enhance. When the strain is $0.5 \%$, the relative magnetorheological effect of MRSP 5 reaches $352 \%$ at most; nevertheless, if the shear strain increases to $10 \%$, the relative magnetorheological effect of MRSP 4 reaches as high as $617 \%$, and the adjustable range of the magnetic field is relatively wide. Consequently, it is beneficial to obtain great magnetorheological effect when the volume fraction of the soft magnetic particle is high.

\subsection{Slow and Fast Mechanical Properties of the STMR} Damper. By comparing the rate sensitive characteristic and magnetorheological effect of each MRSP samples, the MRSP 5 sample with high magnetorheological effect was finally selected as the filling material in the main cylinder tube of the STMR damper. Since there was no soft magnetic particles filled in MRSP 0 sample, due to its higher relative shear stiffening effect, it was regarded as the filling materials for the accessory cylinder tube of the STMR damper. For the STMR damper with the locking function, when the relative speed rate of the piston to the cylinder is slower than $1 \mathrm{~mm} / \mathrm{s}$, it is considered as a slow testing, but when the speed rate is greater than $1 \mathrm{~mm} / \mathrm{s}$, it is regarded as a fast testing. Firstly, in order to meet the requirements of the slow testing, the control rates were set constantly as $0.033 \mathrm{~mm} / \mathrm{s}, 0.083 \mathrm{~mm} / \mathrm{s}, 0.166 \mathrm{~mm} / \mathrm{s}$, $0.33 \mathrm{~mm} / \mathrm{s}, 0.66 \mathrm{~mm} / \mathrm{s}$, and $0.83 \mathrm{~mm} / \mathrm{s}$, respectively. Figure 7 is the force-displacement curve of the STMR damper when the control rate is $0.033 \mathrm{~mm} / \mathrm{s}$, from which it is clear that the whole region is approximately divided into three parts: elastic region, viscoelastic region, and viscous region. The forcedisplacement curve displays a linear relationship in the elastic region, a nonlinear relationship in the viscoelastic region, and gradually reaches stability in the viscous region, which tends to a certain value. According to the forcedisplacement curve of the elastic region and Hooke's law, the elastic stiffness $K$ of the STMR damper at different tensile rates is calculated. Figure 8 shows the relationship between the elastic stiffness of the STMR damper and the 

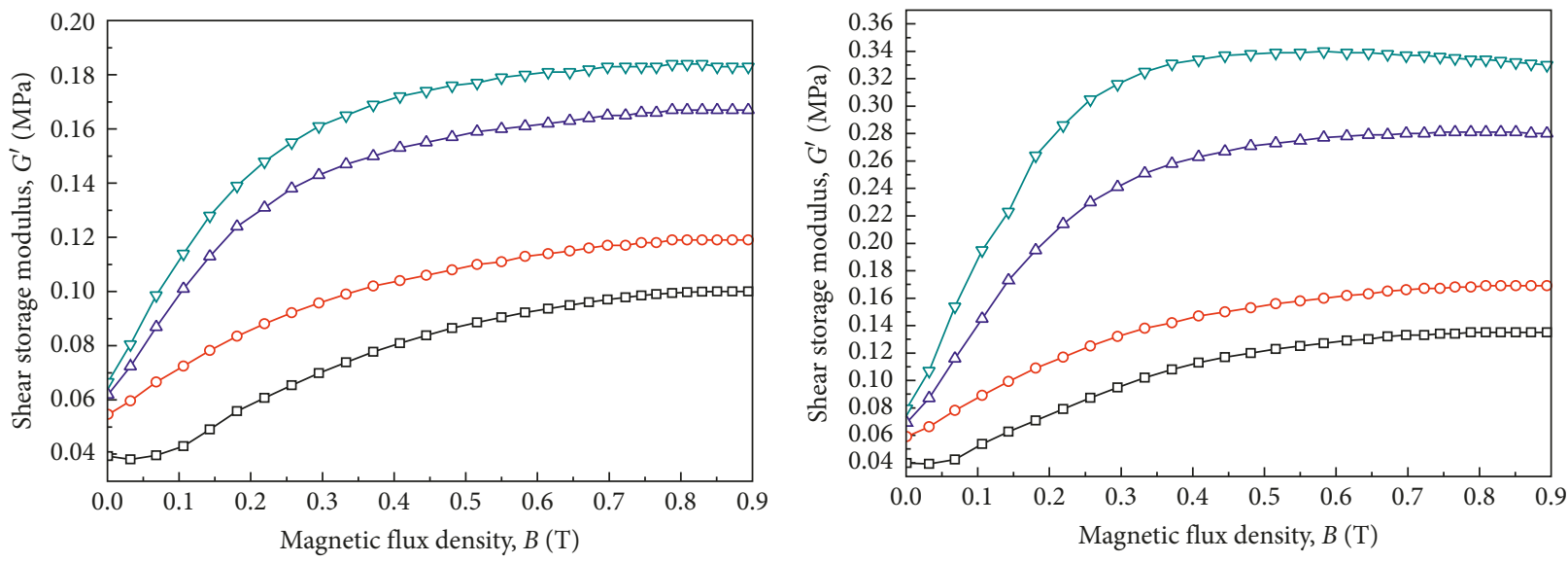

$$
\begin{array}{llrl}
\neg-\gamma=10 \% & \rightarrow \gamma=1 \% \\
\multimap-\gamma=5 \% & \rightarrow \gamma=0.5 \%
\end{array}
$$

(a)

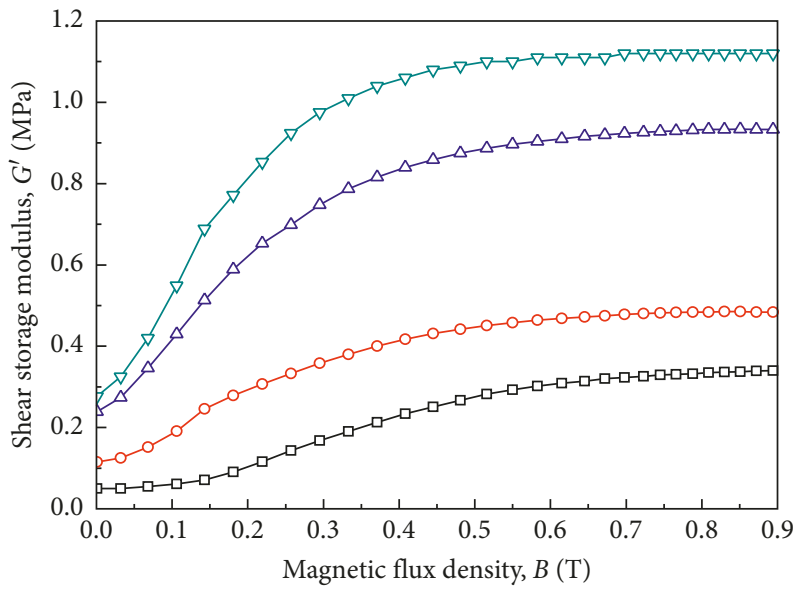

$$
\begin{aligned}
& \rightarrow-\gamma=10 \% \\
& \multimap \gamma=5 \% \\
& \begin{array}{l}
\neg \quad \gamma=1 \% \\
\neg-\gamma=0.5 \%
\end{array}
\end{aligned}
$$

(c)

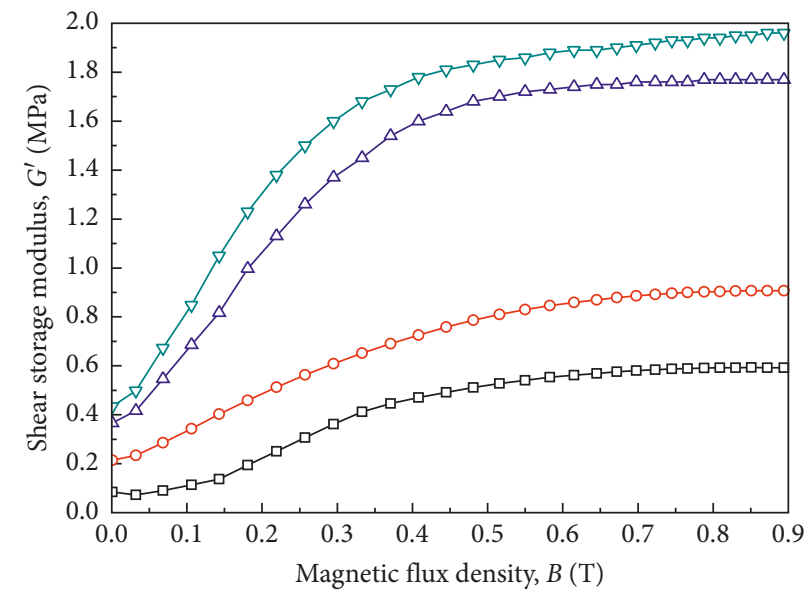

(b)

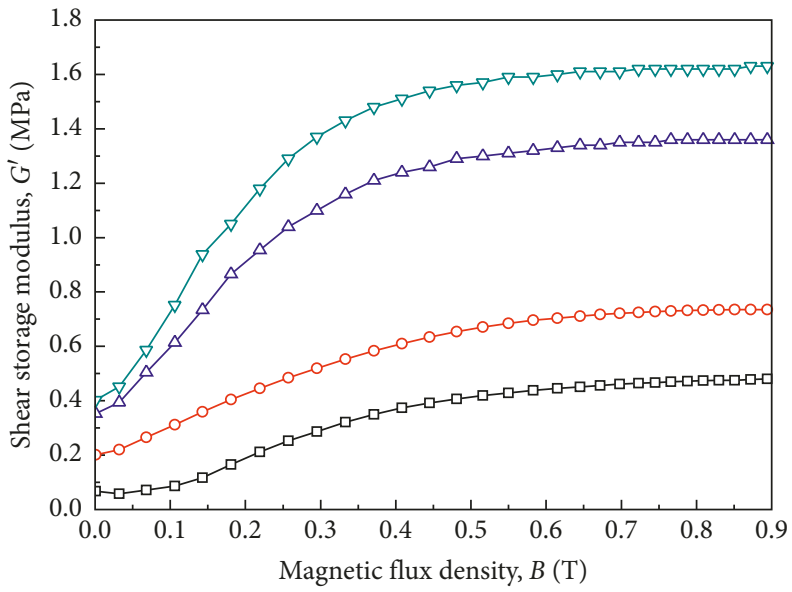

$$
\begin{aligned}
& \neg-\gamma=10 \% \\
& \neg-\gamma=1 \% \\
& \rightarrow-\gamma=0.5 \%
\end{aligned}
$$

(d)

$$
\begin{aligned}
& \rightarrow-\gamma=10 \% \\
& \neg-\gamma=1 \% \\
& \multimap-\gamma=5 \% \\
& \rightarrow \quad \gamma=0.5 \%
\end{aligned}
$$

(e)

FIGURE 6: The shear storage modulus of MRSP samples as a function of magnetic flux density at different shear strains. (a) MRSP 1, (b) MRSP 2, (c) MRSP 3, (d) MRSP 4, and (e) MRSP 5. 
TABle 4: $G_{\max }^{\prime}, G_{\min }^{\prime}$, AMRe, and RMRe of the MRSP samples.

\begin{tabular}{|c|c|c|c|c|c|}
\hline Samples & $\begin{array}{c}\text { Shear } \\
\text { strain, } \\
\gamma\end{array}$ & $\begin{array}{c}G_{\max }^{\prime} \\
(\mathrm{MPa})\end{array}$ & $\begin{array}{l}G_{\text {min }}^{\prime} \\
(\mathrm{MPa})\end{array}$ & $\begin{array}{l}\text { AMRe } \\
(\mathrm{MPa})\end{array}$ & $\begin{array}{c}\text { RMRe } \\
(\%)\end{array}$ \\
\hline \multirow{4}{*}{ MRSP 1} & $0.5 \%$ & 0.184 & 0.0666 & 0.1174 & 176.28 \\
\hline & $1 \%$ & 0.167 & 0.0619 & 0.1051 & 169.79 \\
\hline & $5 \%$ & 0.119 & 0.0547 & 0.0643 & 117.55 \\
\hline & $10 \%$ & 0.100 & 0.0393 & 0.0607 & 154.45 \\
\hline \multirow{4}{*}{ MRSP 2} & $0.5 \%$ & 0.340 & 0.0796 & 0.2604 & 327.14 \\
\hline & $1 \%$ & 0.281 & 0.0692 & 0.2118 & 306.07 \\
\hline & $5 \%$ & 0.169 & 0.0590 & 0.1100 & 186.44 \\
\hline & $10 \%$ & 0.135 & 0.0398 & 0.0952 & 239.20 \\
\hline \multirow{4}{*}{ MRSP 3} & $0.5 \%$ & 1.120 & 0.2770 & 0.8430 & 304.33 \\
\hline & $1 \%$ & 0.934 & 0.2390 & 0.6950 & 290.79 \\
\hline & $5 \%$ & 0.484 & 0.1150 & 0.3690 & 320.87 \\
\hline & $10 \%$ & 0.340 & 0.0498 & 0.2902 & 582.73 \\
\hline \multirow{4}{*}{ MRSP 4} & $0.5 \%$ & 1.630 & 0.4020 & 1.2280 & 305.47 \\
\hline & $1 \%$ & 1.360 & 0.3530 & 1.0070 & 285.27 \\
\hline & $5 \%$ & 0.735 & 0.2010 & 0.5340 & 265.67 \\
\hline & $10 \%$ & 0.480 & 0.0669 & 0.4131 & 617.49 \\
\hline \multirow{4}{*}{ MRSP 5} & $0.5 \%$ & 1.960 & 0.4340 & 1.5260 & 351.61 \\
\hline & $1 \%$ & 1.770 & 0.3660 & 1.4040 & 383.61 \\
\hline & $5 \%$ & 0.907 & 0.2140 & 0.6930 & 323.83 \\
\hline & $10 \%$ & 0.592 & 0.0843 & 0.5077 & 602.25 \\
\hline
\end{tabular}

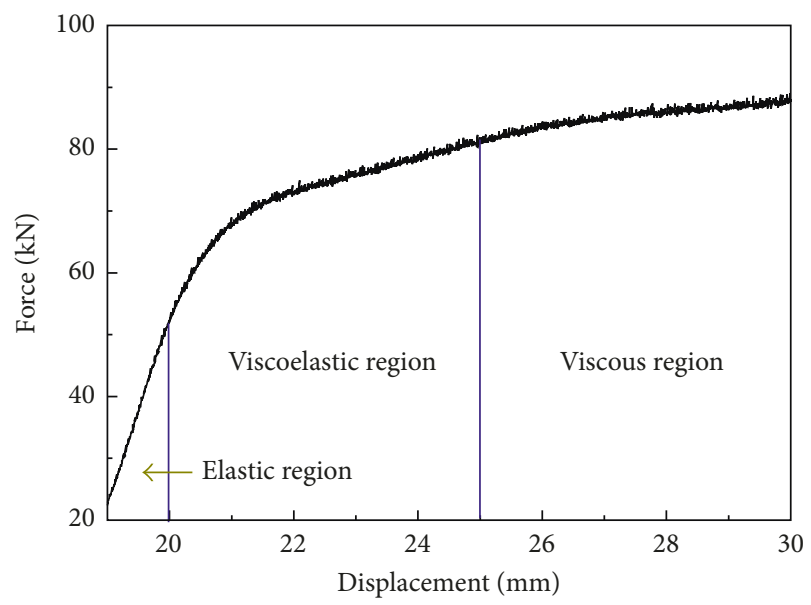

FIGURE 7: Division of the displacement-resistance region.

control rate, from which it is detected that the greater the control rate is, the greater the elastic stiffness of the STMR damper becomes. When the set control rate equals to $0.033 \mathrm{~mm} / \mathrm{s}$, elastic stiffness tends to be less than $30 \mathrm{kN} / \mathrm{mm}$; however, when the control rate is up to $0.83 \mathrm{~mm} / \mathrm{s}$, the elastic stiffness exceeds $65 \mathrm{kN} / \mathrm{mm}$, which is twice as much as that of the former. Accordingly, it proves that under the condition of a slow testing, the STMR damper exhibits a certain rate sensitive characteristic.

The fast testing displays that the STMR damper can be instantaneously locked at a certain rate to transfer the designed load. According to AASHTO, when a fast testing is carried out, the locking distance should be within $12 \mathrm{~mm}$ [19]. Figure 9 shows the force-displacement curves with

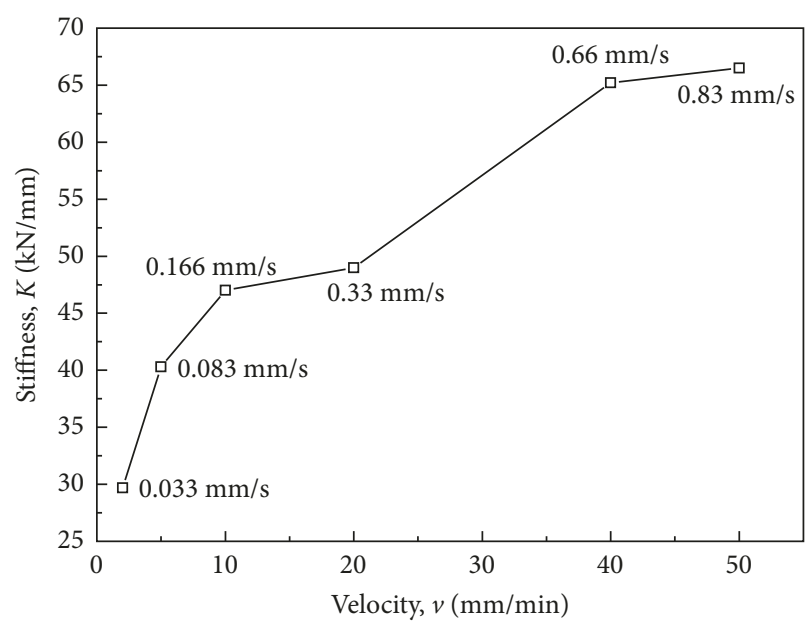

FIGURE 8: Relationship between velocity and spring stiffness.

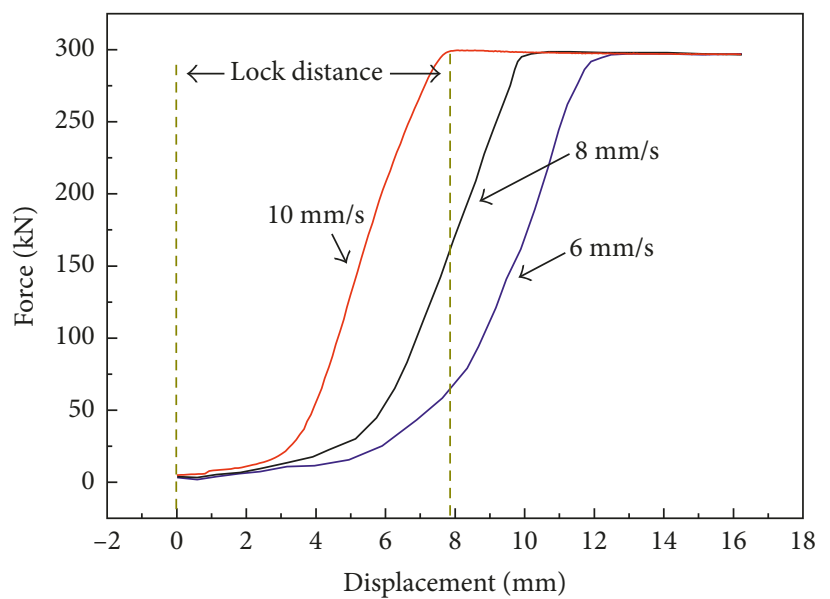

FIGURE 9: The relationship between displacement and resistance force.

a constant control rate of $6 \mathrm{~mm} / \mathrm{s}, 8 \mathrm{~mm} / \mathrm{s}$ and $10 \mathrm{~mm} / \mathrm{s}$, respectively. It is observed that when the force is loaded from 0 to $300 \mathrm{kN}$, the locking distances under the three control rates are all less than $12 \mathrm{~mm}$, which is in full compliance with the provisions of AASHTO. Nevertheless, when the control rate increases, the lock distance and locking time tend to shorten. The locking distance under the control rate of $10 \mathrm{~mm} / \mathrm{s}$ is approximately $8 \mathrm{~mm}$, and the locking time is only $0.8 \mathrm{~s}$, which achieves instant locking, while on the other hand, the lock times of the other two groups under the control rates are both more than one second. Therefore, combined with these experimental results, the developed STMR damper accomplishes the locking function within a short time and distance, which reveals that the STMR damper can be simplified as a "rate switch" with a locking rate of $10 \mathrm{~mm} / \mathrm{s}$, meaning that instant locking happens when this rate is exceeded.

4.4. Dynamic Mechanical Properties of the STMR Damper. When the amplitude is within the range of the maximum compression of the butterfly spring, only the main piston of 


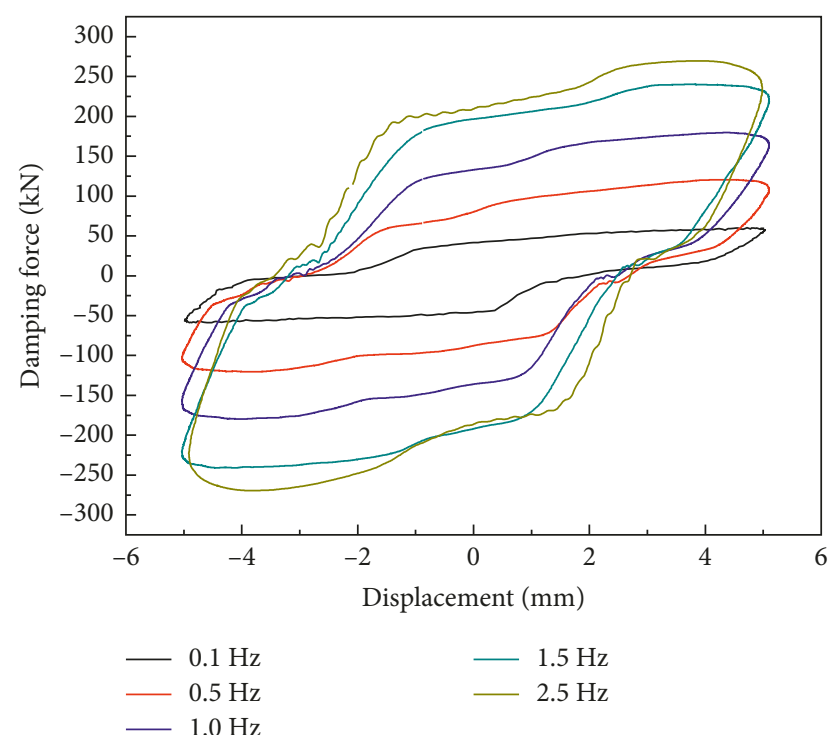

FIGURE 10: Relationship between the damping force and displacement for the STMR damper.

the STMR damper works. When the amplitude exceeds the maximum compression of the butterfly spring, the main and accessory pistons work together, resulting in a greater output of damping force. Since the interior of the STMR damper is filled by MRSPs with the rate sensitive characteristic, it is necessary to confirm the dynamic rate sensitive performance. So, the excitation frequency of $0.1 \mathrm{~Hz}, 0.5 \mathrm{~Hz}, 1.0 \mathrm{~Hz}$, $1.5 \mathrm{~Hz}$, and $2.5 \mathrm{~Hz}$ were, respectively, applied under a displacement of $5 \mathrm{~mm}$. The experimental results are displayed in Figure 10. From the experimental curve, it is sensed that under the condition of small displacement, within a frequency range of $0.1 \mathrm{~Hz}-2.5 \mathrm{~Hz}$, the damping force changes from 60.3 to $269.5 \mathrm{kN}$. The higher the excitation frequency is, the greater the shear rate of materials in the interior of the damper comes to be, the larger the damping force becomes, and the more apparent the rate sensitive characteristic turns out to be. Besides, the ratio between the maximum and minimum damping force is 4.5 , showing that when the excitation frequency is more than $1.5 \mathrm{~Hz}$, the damping force gradually tends to saturation, and the change range is limited, which is consistent with the rate sensitive performance of the MRSP samples. When the excitation frequency enhances, the envelope area of the damping force-displacement curve inclines to enlarge, indicating that the energy dissipation capacity of the STMR damper becomes stronger, and the frequency directly affects the energy dissipation capacity of the STMR damper. The force of the butterfly spring is superimposed on the STMR damper, which leads to the slant of the hysteresis curve.

In order to validate the adjustable characteristic of the mechanical properties for the STMR damper under the effect of the magnetic field, the dynamic mechanical properties were investigated under different currents, during which the same displacement control was adopted, and each working condition was circulated for 10 times. The testing conditions were as follows: the displacement was $5 \mathrm{~mm}$, the frequencies were $0.1 \mathrm{~Hz}, 0.5 \mathrm{~Hz}, 1.0 \mathrm{~Hz}$, and $1.5 \mathrm{~Hz}$, and a current of $0 \mathrm{~A}$, $1 \mathrm{~A}, 2 \mathrm{~A}$, and $3 \mathrm{~A}$ was applied in each case, respectively. When the displacement was $55 \mathrm{~mm}$ and the frequency was $0.1 \mathrm{~Hz}$, a current of $0 \mathrm{~A}, 1 \mathrm{~A}, 2 \mathrm{~A}$, and $3 \mathrm{~A}$ was similarly applied; nevertheless, when the input current increased in sequence, the magnetic flux density in the working gap of the STMR damper also enhanced and the damping force of the damper also correspondingly magnified as well. Figure 11 presents the experimental results under the above testing conditions, showing from the damping force-displacement curves that whether it is under the condition of small displacement or large displacement, and the STMR damper exhibits certain mechanical property of magnetic field controllability.

As shown in Figure 11, frequency is an important factor that affects the adjustable range of the damping force of the STMR damper under a small displacement of $5 \mathrm{~mm}$. In Figure 11(a), the excitation frequency is $0.1 \mathrm{~Hz}$, presenting that when the input current changes from 0 to $3 \mathrm{~A}$, the variation range of the damping force is $60.3-189.3 \mathrm{kN}$, and the ratio between the maximum and minimum damping force is approximately 3.1. In Figures 11(b)-11(d), the excitation frequencies are $0.5 \mathrm{~Hz}, 1.0 \mathrm{~Hz}$, and $1.5 \mathrm{~Hz}$, respectively, revealing the fact that when the current changes from 0 to $3 \mathrm{~A}$, the ratio between the maximum and minimum damping force becomes 2.0, 1.4, and 1.2, respectively. Accordingly, the increase of frequency directly affects the adjustable range of the damper under the excitation of the magnetic field, which demonstrates that the higher the frequency is, the narrower the adjustable range turns out to be. This is for the reason that the high excitation frequency makes the filling materials to stiffen, and the soft magnetic particles in the magnetic field are chain blocked, which is not advantageous to stimulate the magnetorheological effect, and thereby makes the adjustable range of the damper under magnetic field narrow down. In Figure 11(e), under the condition of a displacement of $55 \mathrm{~mm}$ with low frequency and large displacement, the damper presents the obvious characteristic of magnetic field controllability. When the input current changes from 0 to $3 \mathrm{~A}$, the variation range of the damping force is $212.8-272.1 \mathrm{kN}$, and the ratio between the maximum and minimum damping force is approximately 1.3. When the damper is under the condition of large displacement, since the butterfly spring works together with the main and accessory cylinder tubes after the compression limit, the hysteresis curve displays a certain sag in the positive and negative strokes.

In the structural vibration control, as the external excitation frequency is not enough to make the STMR damper induce the speed locking, it is given full play to the adjustment ability of the damper in the magnetic field, which indicates that the STMR damper can be simplified to a larger traditional MR damper.

4.5. Dynamic Hysteretic Mechanical Model for the STMR Damper. The dynamic damping force of the STMR damper can be decomposed into a superposition of three components of force: the first component of force refers to applied 

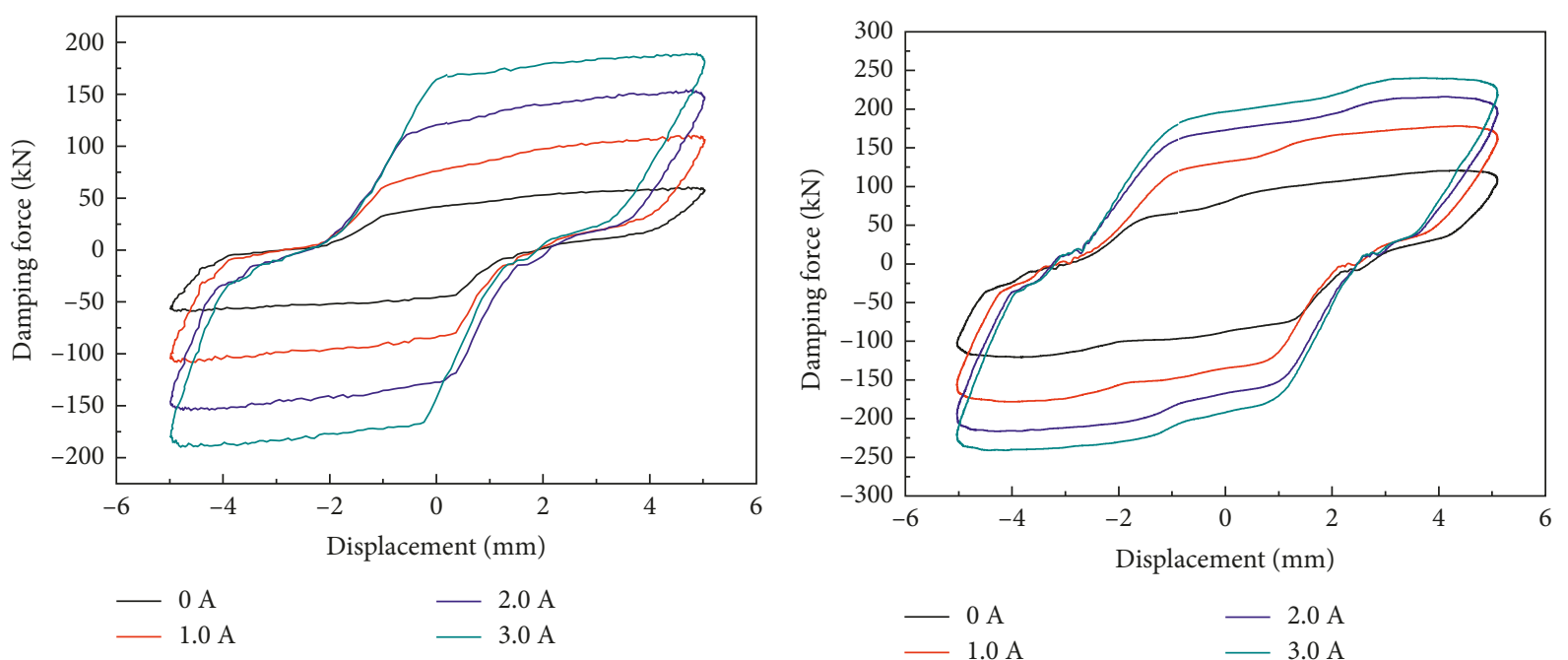

(a)
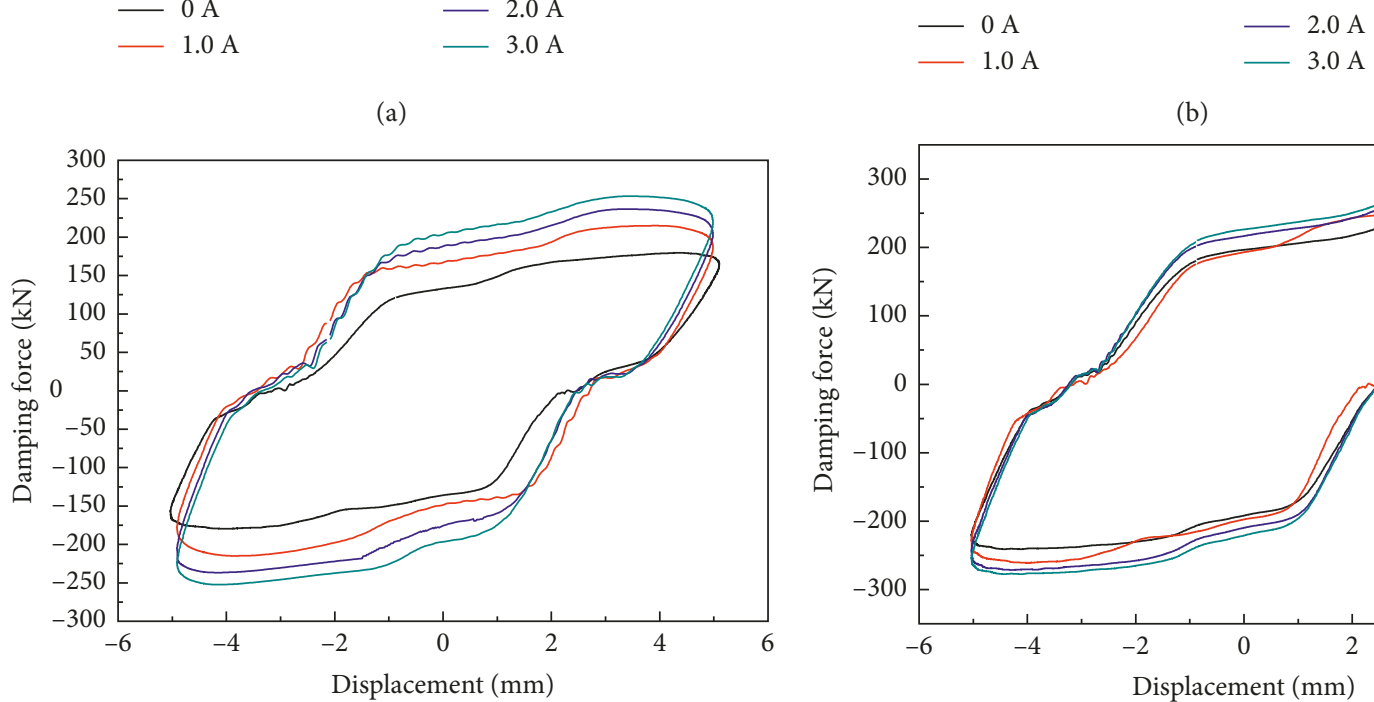

(b)


$-2.0 \mathrm{~A}$

$-0 \mathrm{~A}$

$-2.0 \mathrm{~A}$

$-1.0 \mathrm{~A}$

(c)

(d)


(e)

FIGURE 11: Relationship between damping force and displacement for the STMR damper at different frequencies and displacements: (a) $0.1 \mathrm{~Hz}, 5 \mathrm{~mm}$; (b) $0.5 \mathrm{~Hz}, 5 \mathrm{~mm}$; (c) $1.0 \mathrm{~Hz}, 5 \mathrm{~mm}$; (d) $1.5 \mathrm{~Hz}, 5 \mathrm{~mm}$; (e) $0.1 \mathrm{~Hz}, 55 \mathrm{~mm}$. 
force $f_{\mathrm{mr}}$, which is produced by the magnetorheological effect of the material, which is related to the current or exerted magnetic field strength; the second component of force $f_{\mathrm{pm}}$ stands for the applied force to describe the characterization of polymer properties, which is connected with external excitation rate or strain rate; as for $f_{\text {bs }}$, it means the additional force of the butterfly spring, which satisfies with Hooke's Law.

The first component of force $f_{\mathrm{mr}}$ can be expressed as

$$
f_{\mathrm{mr}}=k_{1}^{\prime} u+c^{\prime} \dot{u}+f_{\mathrm{p}}
$$

where $k_{1}^{\prime}$ and $c^{\prime}$ are the stiffness and damping coefficients depending on the magnetic field strength, respectively; $u$ and $\dot{u}$ stand for the displacement and speed rate; $f_{\mathrm{p}}$ is the hysteretic subitem, which is controlled by the following Bouc-Wen differential equation:

$$
\begin{aligned}
f_{\mathrm{p}}^{\prime} & =\alpha \dot{u}-\beta \dot{u}\left|f_{\mathrm{p}}\right|^{n}-\gamma|\dot{u}| f_{\mathrm{p}}\left|f_{\mathrm{p}}\right|^{n-1} \\
& =\left\{\alpha-\left[\beta+\gamma \operatorname{sgn}\left(\dot{u} f_{\mathrm{p}}\right)\right]\left|f_{\mathrm{p}}\right|^{n}\right\} \dot{u},
\end{aligned}
$$

where $\alpha, \beta, \gamma$, and $n$ are all the parameters to control the shape of the hysteretic curve.

The second component of force $f_{\mathrm{pm}}$ refers to the material viscoelasticity or nonlinear stiffness characteristic, which can be expressed as

$$
f_{\mathrm{pm}}=k_{1}^{\prime \prime} u+k_{3}^{\prime \prime} u+c^{\prime \prime} \dot{u},
$$

where $k_{1}^{\prime \prime}, k_{3}^{\prime \prime}$, and $c^{\prime \prime}$ are the stiffness and damping coefficients depending on the speed rate or the strain rate, respectively.

The third component of force $f_{\text {bs }}$ means the additional force of the butterfly spring, when under the situation that the excitation amplitude is less than the maximum compression of the butterfly spring; according to Hooke's law, it is expressed as

$$
f_{\mathrm{bs}}=k_{\mathrm{bs}} u,
$$

where $k_{\mathrm{bs}}$ stands for the stiffness of the butterfly spring.

Based on (4), (6), and (7), the damping force of the STMR damper can be expressed as

$$
f=f_{\mathrm{mr}}+f_{\mathrm{pm}}+f_{\mathrm{bs}}=\left(k_{1}+k_{\mathrm{bs}}\right) u+k_{3} u^{3}+c \dot{u}+\lambda f_{\mathrm{p}},
$$

where $k_{1}=k_{1}^{\prime}+k_{1}^{\prime \prime} ; k_{3}=k_{3}^{\prime \prime} ; c=c^{\prime}+c^{\prime \prime}$; and $\lambda$ represents the proportional coefficient between the hysteretic and nonhysteretic force. All the stiffness and damping coefficients depend on the strain rate and magnetic field density.

For the dynamic mechanical properties of the STMR damper, it can be considered that the shear storage modulus of the MRSPs contributes to the stiffness part of the device structure, whereas the damping characteristic of the material contributes to the damping part of the device structure. Consequently, in (8), the stiffness coefficients $k_{1}$ and $k_{3}$, damping coefficient $c$, and ratio coefficient $\lambda$ can be rewritten into functions of magnetic field and speed rate as below, respectively. Furthermore, related studies revealed that stiffness and damping are almost linearly dependent on the external magnetic field and strain rate [20]:

$$
\begin{aligned}
& k_{1}=k_{10}\left(H_{\mathrm{e}}\right)+k_{11}\left(H_{\mathrm{e}}\right)|\dot{u}|+k_{12}\left(H_{\mathrm{e}}\right)|\dot{u}|^{2}, \\
& k_{3}=k_{30}\left(H_{\mathrm{e}}\right)+k_{31}\left(H_{\mathrm{e}}\right)|\dot{u}|, \\
& c=c_{0}\left(H_{\mathrm{e}}\right)+c_{1}\left(H_{\mathrm{e}}\right)|\dot{u}|, \\
& \lambda=\lambda_{0}\left(H_{\mathrm{e}}\right)+\lambda_{1}\left(H_{\mathrm{e}}\right)|\dot{u}|,
\end{aligned}
$$

where $k_{10}, k_{11}, k_{12}, k_{30}, k_{31}, c_{0}, c_{1}, \lambda_{0}$, and $\lambda_{1}$ are approximated as the linear equation of the external magnetic field $H_{\mathrm{e}}$.

The displacement hysteresis phenomenon of the STMR damper is caused by the subitem $f_{\mathrm{p}}$ of the hysteretic force; therefore, in combination with (5), the hysteretic force can be expressed as

$$
\begin{aligned}
F_{1}\left(f_{\mathrm{p}}\right) & =u-u_{+} \\
F_{2}\left(f_{\mathrm{p}}\right) & =u-u_{+} \\
F_{3}\left(f_{\mathrm{p}}\right) & =u-u_{-} \\
F_{3}\left(f_{\mathrm{p}}\right) & =u-u_{-} \\
\text {or } f_{\mathrm{p}} & =F_{1}^{-1}\left(u-u_{+}\right), \quad \dot{u} \geq 0, \quad f_{\mathrm{p}} \geq 0 \\
f_{\mathrm{p}} & =F_{2}^{-1}\left(u-u_{+}\right), \quad \dot{u} \geq 0, \quad f_{\mathrm{p}} \leq 0 \\
f_{\mathrm{p}} & =F_{3}^{-1}\left(u-u_{-}\right), \quad \dot{u} \leq 0, \quad f_{\mathrm{p}} \geq 0 \\
f_{\mathrm{p}} & =F_{4}^{-1}\left(u-u_{-}\right), \quad \dot{u} \leq 0, \quad f_{\mathrm{p}} \leq 0,
\end{aligned}
$$

where $F_{i}\left(f_{p}\right)(i=1,2,3,4)$ represents the function of $f_{\mathrm{p}}$ and $F_{i}^{-1}\left(f_{\mathrm{p}}\right)$ means the inverse function of $F_{i}\left(f_{\mathrm{p}}\right)$. Furthermore, $u_{+}$and $u_{-}$, respectively, refer to the lagging displacement produced in the positive and negative directions of the equilibrium position. In the testing process, the upward of the balanced position is positive, while the downward of the balanced position is negative. In a cycle, once the peak and valley values of the displacement are equal and the lagging displacement of the positive and negative directions reaches equivalence, the hysteresis curve presents the symmetric characteristic. Besides, when $n=1$ and $\beta=\gamma,(5)$ can be simplified to

$$
f_{\mathrm{p}}= \begin{cases}\frac{\alpha}{\beta+\gamma}\left[1-e^{-(\beta+\gamma)\left(u-u_{+}\right)}\right], & \dot{u} \geq 0, \\ \alpha\left(u-u_{+}\right), & f_{\mathrm{p}} \geq 0 \\ \alpha\left(u-u_{-}\right), & \dot{u} \geq 0, \quad f_{\mathrm{p}} \leq 0 \\ \frac{-\alpha}{\beta+\gamma}\left[1-e^{(\beta+\gamma)\left(u-u_{-}\right)}\right], & \dot{u} \leq 0, \quad f_{\mathrm{p}} \geq 0\end{cases}
$$

Therefore, according to (8) and (14), the damping force of the STMR damper can be ultimately expressed as 


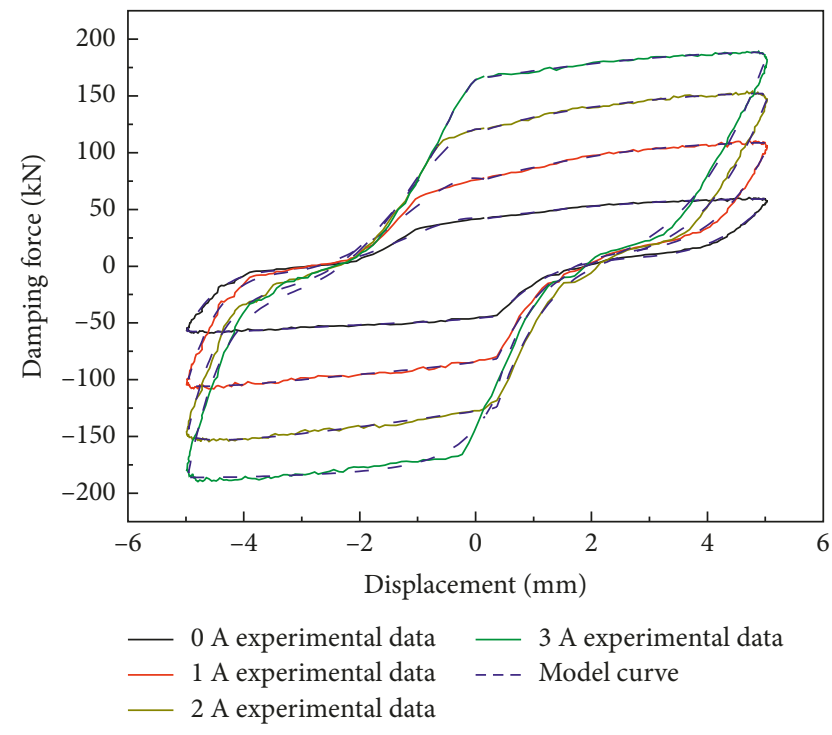

TABLE 5: Results of the parameter identification.

\begin{tabular}{lcccc}
\hline Parameters & $I=0 \mathrm{~A}$ & $I=1 \mathrm{~A}$ & $I=2 \mathrm{~A}$ & $I=3 \mathrm{~A}$ \\
\hline$k_{10}$ & -0.15 & -0.00049 & 5.35 & -48.87 \\
$k_{11}$ & 33.59 & 5.85 & -13.03 & 29.70 \\
$k_{12}$ & -57.71 & -82.02 & 14.16 & -1.03 \\
$k_{30}$ & 0.45 & 0.022 & 0.25 & -0.14 \\
$k_{31}$ & -0.43 & 0.027 & -0.34 & 0.09 \\
$c_{0}$ & -45.23 & 238.50 & 61.14 & 307.36 \\
$c_{1}$ & 143.15 & 0.31 & 65.55 & -93.70 \\
$\lambda_{0}$ & 0.00083 & 0.94 & 2.01 & -1.45 \\
$\lambda_{1}$ & 23.20 & 60.74 & 2.55 & 26.09 \\
$\alpha$ & 1.23 & 1.35 & 0.38 & 1.02 \\
$\beta$ & 0.033 & 0.022 & 0.50 & 0.01 \\
$\lambda$ & 0.033 & 0.022 & 0.50 & 0.01 \\
$n$ & 1 & 1 & 1 & 1 \\
$k_{\mathrm{bs}}$ & 0.40 & 0.40 & 0.40 & 0.40 \\
\hline
\end{tabular}

Figure 12: The relationship between the model curve and experimental data of the STMR damper.

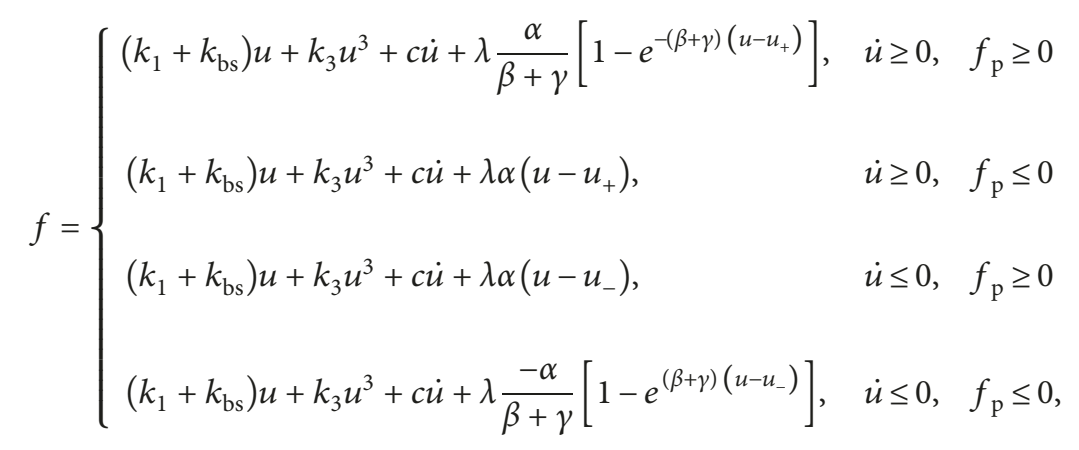

As a result, the stiffness coefficients $k_{1}$ and $k_{3}$, the damping coefficient $c$, and the ratio coefficient $\lambda$ are expanded from (9)-(12), respectively.

Marquardt algorithm was adopted to carry out the parameter identification on the damping mechanical model of the STMR damper. Low frequency and small displacement experimental data were selected, among which the excitation frequency was $0.1 \mathrm{~Hz}$, the amplitude was $5 \mathrm{~mm}$, and the current input was $0 \mathrm{~A}, 1 \mathrm{~A}, 2 \mathrm{~A}$, and $3 \mathrm{~A}$, respectively. From the experimental data, it can be perceived that the lagging displacement in both positive and negative directions is $2 \mathrm{~mm}$, whereas 14 parameters based on the symmetric dynamic hysteretic mechanical model were identified. The identification results are listed in Table 5. Figure 12 displays the comparison between the dynamic hysteresis experimental curves of the STMR damper and the model hysteresis curve acquired by parameter identification, presenting that the model curve stands in good agreement with the experimental data, which further validates the correctness of the multiparameter and symmetric dynamic hysteretic model, and indicates that the method of parameter identification is effective.

\section{Conclusions}

In this work, a novel STMR damper with rate sensitive characteristic (speed locking) and semiactive controlling property was designed and fabricated based on multifunctional composite MRSPs. Both the mechanical properties of MRSPs and the STMR damper were experimentally investigated. Firstly, the MRSP 5 and MRSP 0 samples exhibited the best magnetorheological effect and relative shear stiffening effect, respectively, which were chosen as the fillers of the main cylinder and accessory cylinder. Secondly, through slow and fast experiments, the STMR damper presented an obvious rate sensitive property and realized the speed locking function in a short time and distance when external excitation rate was fast enough. Besides, dynamic experiment results indicated that the damping force of the STMR damper could be controlled by the excitation frequency and the applied magnetic field. Finally, a multiparameter and symmetry hysteretic model was proposed to describe the dynamic hysteretic behavior of the STMR damper, which agreed well with the experimental data. 


\section{Conflicts of Interest}

The authors declare that there are no conflicts of interest regarding the publication of this paper.

\section{Acknowledgments}

This work was supported by Primary Research and Development Plan of Jiangsu Province (Grant no. BE2017167); Natural Science Foundation of Zhejiang Province (Grant no. LY15E080015); National Natural Science Foundation of China (Grant no. 51508237); Natural Science Foundation of Jiangsu Province (Grant no. BK20140560); and Research Foundation for Advanced Talents of Jiangsu University (Grant no. 14JDG161).

\section{References}

[1] F. Guo, C. B. Du, G. J. Yu, and R. P. Li, "The static and dynamic mechanical properties of magnetorheological silly putty," Advances in Materials Science and Engineering, vol. 2016, Article ID 7079698, 11 pages, 2016.

[2] X. Z. Zhang, W. H. Li, and X. L. Gong, "Study on magnetorheological shear stiffening fluid," Smart Materials and Structures, vol. 17, no. 1, p. 015051, 2008.

[3] G. R. Peng, W. H. Li, T. F. Tian, J. Ding, and M. Nakano, "Experimental and modeling study of viscoelastic behaviors of magneto-rheological shear stiffening fluids," Korea-Australia Rheology Journal, vol. 26, no. 2, pp. 149-158, 2014.

[4] S. Wang, W. Jiang, W. Jiang et al., "Multifunctional polymer composite with excellent shear stiffening performance and magnetorheological effect," Journal of Materials Chemistry C, vol. 2, no. 34, pp. 7133-7140, 2014.

[5] Y. Wang, S. Wang, C. Xu, S. Xuan, W. Jiang, and X. Gong, "Dynamic behavior of magnetically responsive shear-stiffening gel under high strain rate," Composites Science and Technology, vol. 127, pp. 169-176, 2016.

[6] B. Sapiński, "Parametric identification of MR linear automotive size damper," Journal of Theoretical and Applied Mechanics, vol. 40, no. 3, pp. 703-722, 2002.

[7] W. L. Qu, S. Q. Qin, J. W. Tu et al., "Intelligent control for braking-induced longitudinal vibration responses of floatingtype railway bridges," Smart Materials and Structures, vol. 18, no. 12, p. 125003, 2009.

[8] W. L. Qu, J. Liu, J. W. Tu, M. Run, and H. Cheng, "Crucial techniques for design of $500 \mathrm{kN}$ large-scale MR damper," Earthquake Engineering and Engineering Vibration, vol. 27, no. 2, pp. 124-130, 2007, in Chinese.

[9] W. L. Qu, M. Run, and J. W. Tu, "Design and simulation of a new full scale MR damper," Journal of Wuhan University of Technology, vol. 29, no. 2, pp. 87-90, 2007, in Chinese.

[10] W. L. Qu, S. Q. Qin, J. W. Tu, J. Liu, and Q. Zhou, “Theory and crucial technologies of intelligent control for response in deck and towers of Wuhan Tianxingzhou cable-stayed bridge subjected to train braking," China Civil Engineering Journal, vol. 43, no. 8, pp. 63-72, 2010, in Chinese.

[11] G. J. Yu, C. B. Du, and T. Sun, "Thermodynamic behaviors of a kind of self-decoupling magnetorheological damper," Shock and Vibration, vol. 2015, Article ID 502747, 9 pages, 2015.

[12] G. J. Yu, C. B. Du, and F. X. Wan, "Design and experimental studies on self-decoupling magneto-rheological damper," Journal of Vibration, Measurement and Diagnosis, vol. 32, no. 3, pp. 426-431, 2012, in Chinese.
[13] G. J. Yu and C. B. Du, "Design and experimental studies on composite magneto-rheological damper," Chinese Quarterly of Mechanics, vol. 35, no. 1, pp. 131-138, 2014, in Chinese.

[14] G. J. Yu, T. Sun, B. Su et al., "Research of architectural structures semi-active control based on SDMR damper," Journal of Chongqing University of Technology (Nature Science), vol. 29, no. 11, pp. 42-50, 2015, in Chinese.

[15] X. Z. Zhang, W. H. Li, and X. L. Gong, "The rheology of shear stiffening fluid (STF) and the dynamic performance of an STF-filled damper," Smart Materials and Structures, vol. 17, no. 3, p. 035027, 2008.

[16] H. Zhou, C. Y. Guo, L. H. Zong et al., "Performance of shear stiffening fluid and a damper as its application," Journal of Vibration and Shock, vol. 32, no. 18, pp. 15-20, 2013, in Chinese.

[17] J. Liang and X. H. Zhang, "Rheological properties of SP in shock transmission application," Journal of Materials in Civil Engineering, vol. 27, no. 9, p. 04014250, 2015.

[18] L. C. Davis, "Model of magnetorheological elastomers," Journal of Applied Physics, vol. 85, no. 6, pp. 3348-3351, 1999.

[19] AASHTO, AASHTO LRFD Bridge Construction Specifications, American Association of State Highway and Transportation Officials, Washington, DC, USA, 2012.

[20] C. Collette, G. Kroll, G. Saive, V. Guillemier, and M. Avraam, "On magnetorheologic elastomers for vibration isolation, damping, and stress reduction in mass-varying structures," Journal of Intelligent Material Systems and Structures, vol. 21, no. 15, pp. 1463-1469, 2010. 


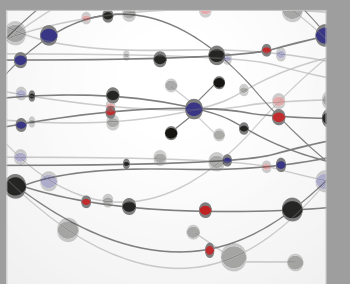

The Scientific World Journal
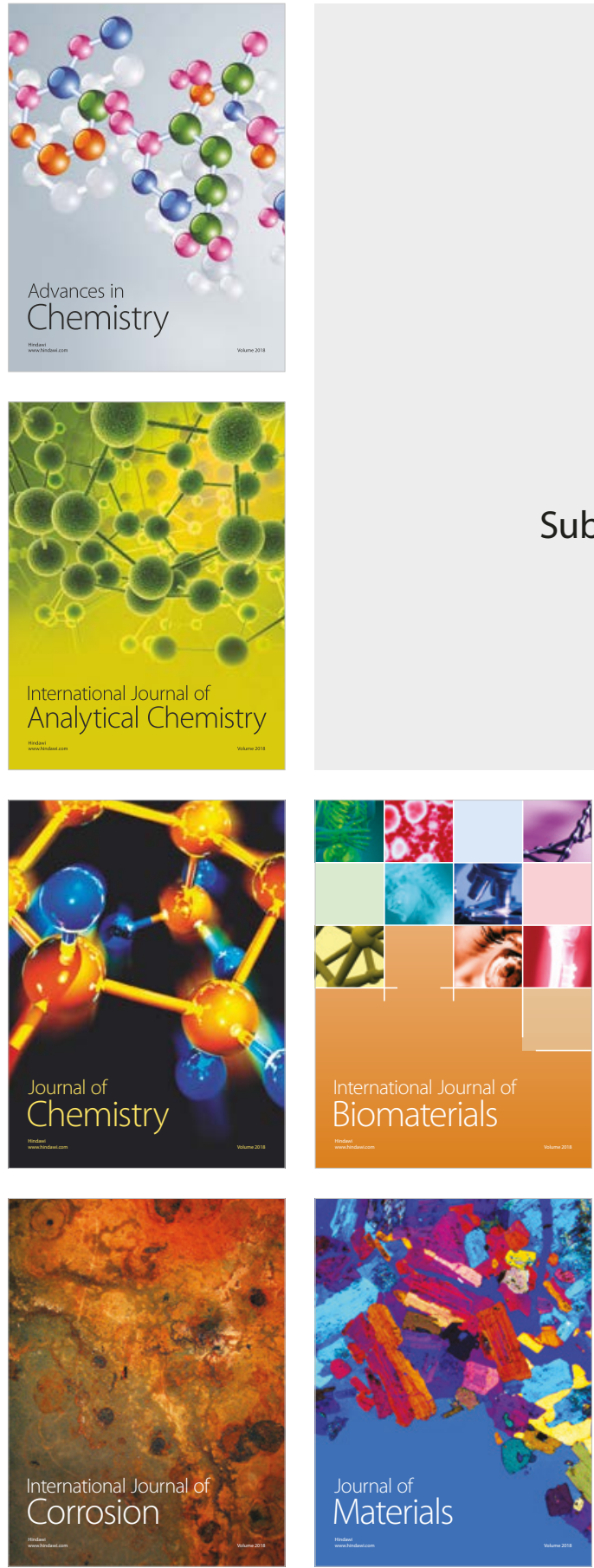

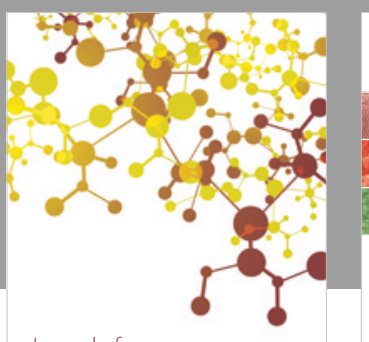

Journal of

Applied Chemistry
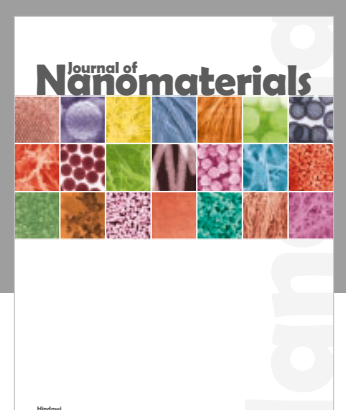

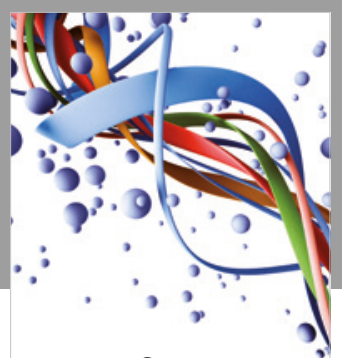

Scientifica

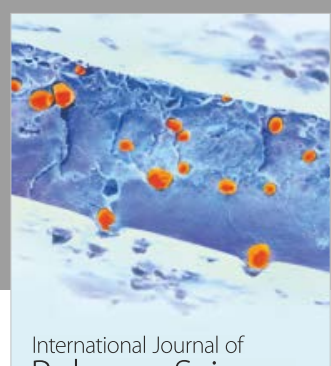

Polymer Science

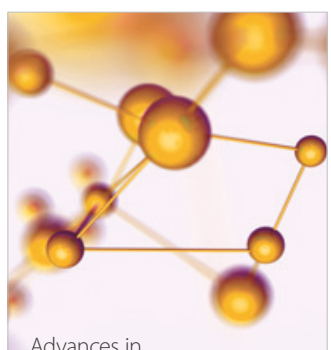

Physical Chemistry
